\title{
Change of the layout of an office of a metallurgical company: simple projects, big solutions
}

\author{
Luiz Carlos da Silva Duarte ${ }^{\mathrm{a}}$, Moacir Eckhardt ${ }^{\mathrm{b}}$ and Giordano Paulo da Motta ${ }^{\mathrm{c}}$ \\ ${ }^{a}$ Agência de Inovação e Tecnologia - AGIT, Universidade Regional do Noroeste do Estado do Rio Grande do Sul - \\ UNIJUÍ, Rua do Comércio, 3000, Bairro Universitário, Ijuí, RS, Brazil \\ ${ }^{\mathrm{b}}$ Colégio Técnico Industrial de Santa Maria - CTISM, Universidade Federal de Santa Maria - UFSM, Faixa de \\ Camobi, Km 9 - Campus Universitário, Santa Maria, RS, Brazil \\ ${ }^{\mathrm{c}}$ Departamento de Engenharia e Ciências Exatas - DCEEng, Universidade Regional do Noroeste do Estado do \\ Rio Grande do Sul - UNIJUÍ, Rua Pref. Rudi Franke, 540, Panambi, RS, Brazil
}

\begin{abstract}
The posture, a good organization and the proper layout of the environment and workplaces have a positive influence on the income of an employee. To develop the work it is used a methodology that addressed the study phases of the theory involving the subject, description of the current situation, preparation of conceptions, choice of design, implementation and reporting of results. Through the project of "Change of the layout of an office of a metallurgical company" there was an intervention in these reported aspects providing improvements in the office, regarding ergonomic, layout, workplace and lighting issues, bringing welfare to the official, with the intent to improve its performance within the company and facilitating its actions, as the company's customer service. The results provided improvements in layout, in the workplace and especially in comfort for the human resources that perform their activities.
\end{abstract}

Keywords: layout, workplace, office, welfare, ergonomic

\section{Introduction}

This change of layout is based on the theory that a static work is one that requires a contraction of muscles to maintain a position (characterized as tiresome) thus producing a high physical stress of the employee as indicated in figure 1 , according to IIDA (1997, p 84).

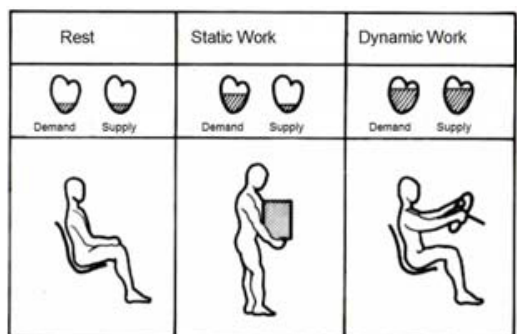

Figure 1: Demand and supply at rest and at work
To minimize discomfort among the people and the workplaces it is necessary to study the repetitive operations of work, allocation of tasks and design of their workplaces and their environment, as ponders DUARTE (2005, p. 16). For correct sizing of a workplace for a sitting person, it was used as perimeter to scale, the critical dimensions proposed in the figure 2 of IIDA (197, p. 109).

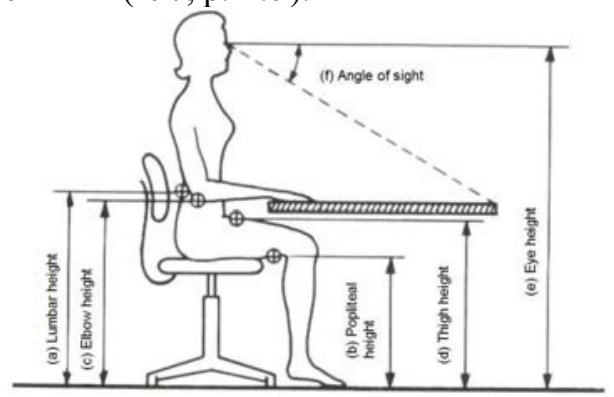

Figure 2: Critical dimensions of the workplace for a sitting person 
Moreover it was observed the line of sight, which is determined by the movement of the pupil and the lighting of the neck and head. When the system is working outside this cone, the head-neck system is turned on, as illustrated in figure 3, of GRANDJEAN (1998, p. 54).

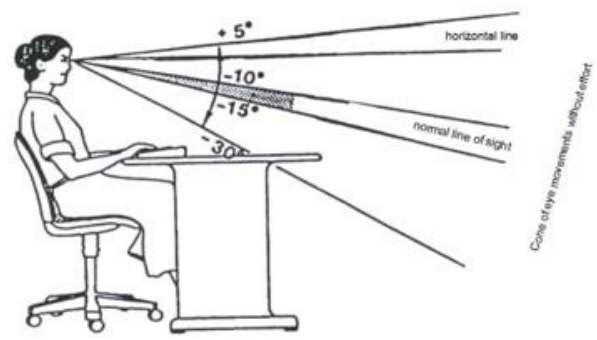

Figure 3: Line of sight for a sitting person

It is still important to note, as says GUIMARÃES (1999, p. 13), that a desktop has two reaching areas, one for a preferred area of work, corresponding to the easier made movement, just for the movement of arms, and the other for the maximum scope that involves simultaneous movements of the torso and shoulders.

Luminaires should be positioned more than thirty degrees above the line of sight and behind the person to avoid the incidence of direct or reflected light on the eye, according to the figure 4 of IIDA (1997, p. 260).

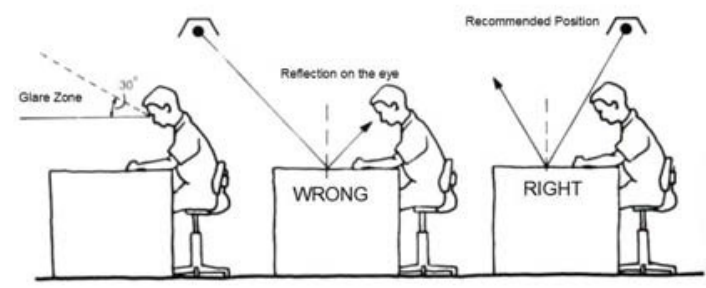

Figure 4: Illumination of the workplace of a sitting person

Offices seats that allow the back of the trunk were preferred, as two-week-long research with six office employees has confirmed. Seat 1: Fixed molded seat with high back. Seat 2: with a slope of two degrees forward and fourteen degrees backward, molded seat with high back. Seat 3: normal office seat, with scalable back. The result of the research is shown in figure 5 of GRANDJEAN (1998, p. 69).

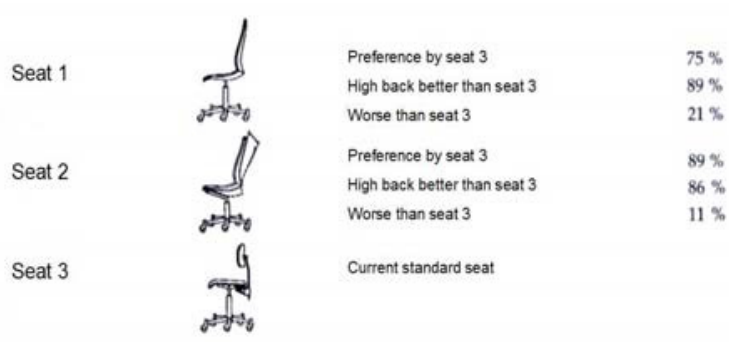

Figure 5: Experimental seats evaluation

Chairs with soft seat were preferred, to allow the minimization of pressure on the ischial tuberosities, as illustrated in figure 6 of IIDA (1997, p. 140).

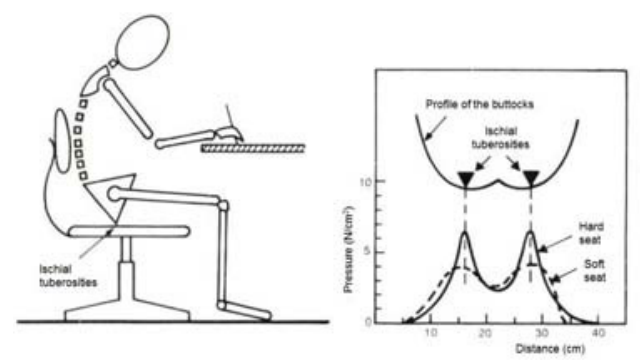

Figure 6: Distribution of pressure on the buttocks

As the workplace have computers, some suggestions for the design of the tables for the work are proposed by IIDA (1997, p. 162), in the figure 7.

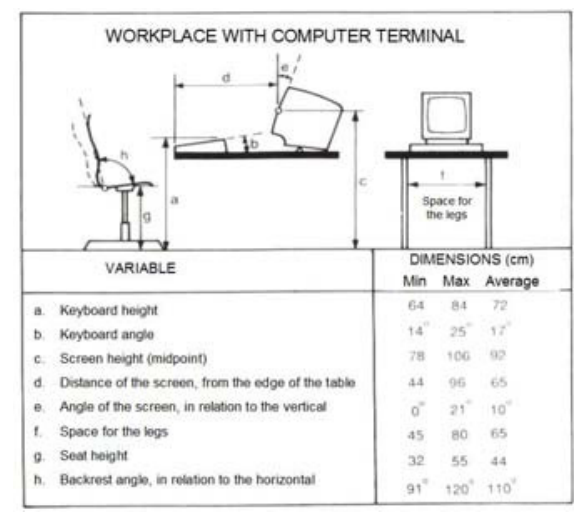

Figure 7: Basic dimensions for workplace with computer

The most important dimensions for a work chair, pointed by CHAFFIN, ANDERSSON \& MARTIN (2001, p. 383), are: (1) top height, (2) lower height, (3) central height, (4) height, (5) width, (6) 
horizontal angle, (7) vertical angle and (8) backrestseat angle, which are shown in figure 8.
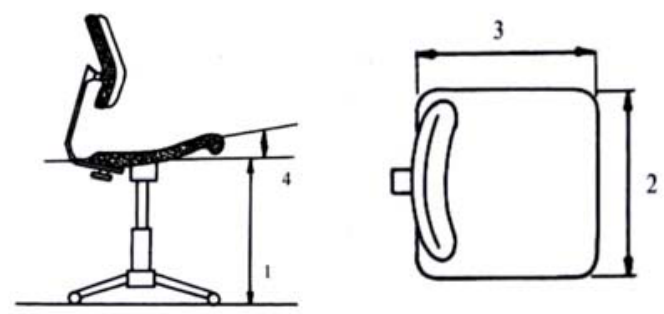

Figure 8: Key dimensions of the seat of a chair.

In the current layout, the disposition of the furniture and equipments is not adequate in relation to the lighting of the ambient, movement of people and the execution of work. In the figure 9 are shown pictures of the current layout.

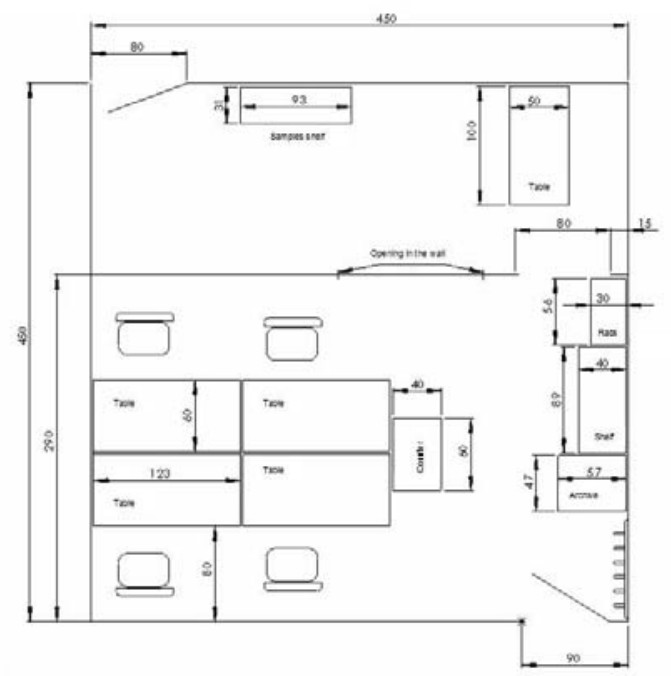

Figure 9: Layout of the current installations of the office

\section{Project elaboration}

The project will be prepared addressing the office of a company, which consists of four work stations distributed at 4,5 x 2,9 meters, totaling 13,05 square meters.

This space contains four tables, with dimensions of $1,2 \times 0,6 \mathrm{~m}$, side and front up against each other, as shown in Figure 10.

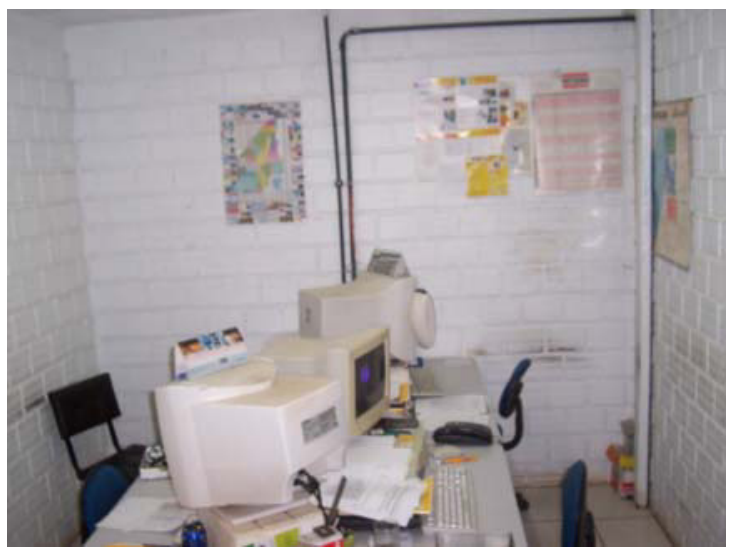

Figure 10: Partial view of the installations of the office.

On the tables, there are three computers, a printer, a FAX machine, a telephone and a cabinet to store documents.

Reclining at the table is a counter, and on the right side of the room, leaning against the wall are a closet, a shelf and an archive, as shown in Figure 11.

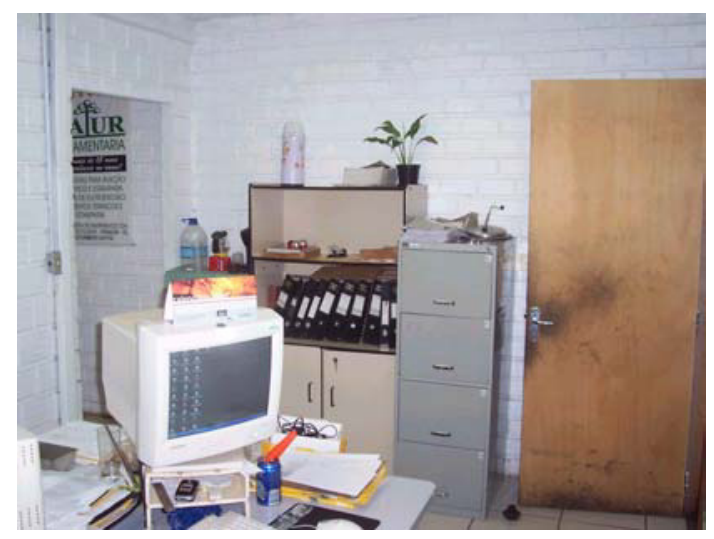

Figure 11: Partial view of the right side of the room.

And in the front hallway is a bookcase for sampling the company's products and a table for customer service.

So it is generated the current layout of the office of the company shown in Figure 13, with some key dimensions and distribution of furniture and equipment.

The problems encountered in the workplace range from the misuse of space, causing a feeling of tightness and trapping the operator, to a poor work ergonomics, due to the position in which are computer monitors and the location of the keyboard, 
that generates a muscle discomfort in the shoulders of the operator due to its high point in relation to the waist line, and also a high discomfort caused by chairs, which are not designed to use in a workplace where the employee needs to spend most time sitting, and executing repeated work, as presented in figure 15. According to SOARES (2009) the repeated work is growing, in order to obtain greater productivity.

The chairs have fixed legs, hindering the movement of people into and out of the job. The lighting was also poorly placed, causing discomfort and a great eye wear, generated due to reflection, as shown in Figure 12.

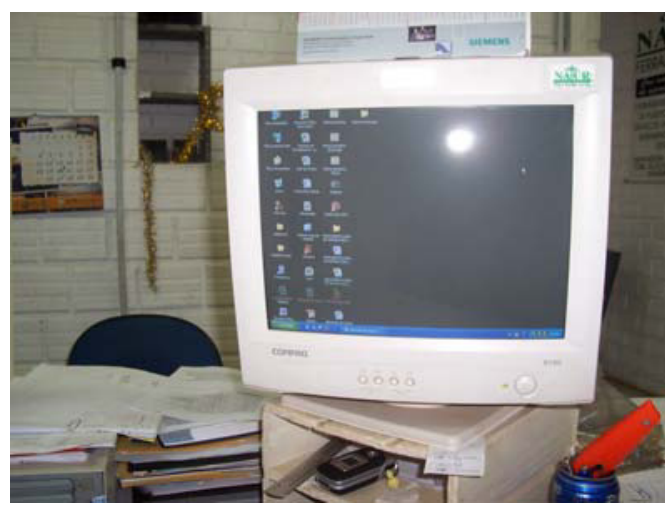

Figure 12: Reflection on the screen

The methodology to carry out the project consisted of developing concepts that address the context of the problem.

In the new project, changes were made in the company office. The first change was the reduction of the wall that separates the room from the central corridor, and the withdrawal of the table to receive customers, positioning the first table so that the employee does not need to raise his post to make the attendance and the new layout (figure 13).

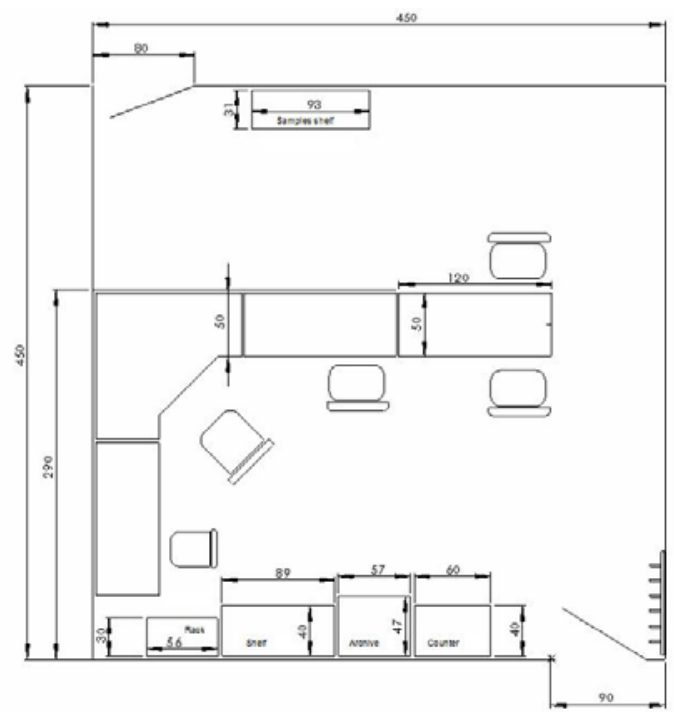

Figure 13: New layout of the room

The old tables were exchanged for tables that contain a slider keyboard place, thus improving your position on the belt line of the operator and reducing its upper area, since it was no longer needed space for the mouse and keyboard. It was also changed the position of the tables, placing them against the wall now, freeing up space in the center of the room.

The bookcase, shelf, desk and archive were placed against the inferior wall of the room, leaving a free corridor between the entrance of the factory and the beginning of the aisle.

As for ergonomics, the improvement was evident, due to better positioning of the arms and shoulders through the regulation of chairs and a lower height above the waist of the keyboard. There was also an increased space for the feet and legs, also helping in the efficiency of the employees.

After examination of the room lighting has been demonstrated that it is not necessary modification, due to the change of the position of the tables with the generated effects seen in Figure 14. 


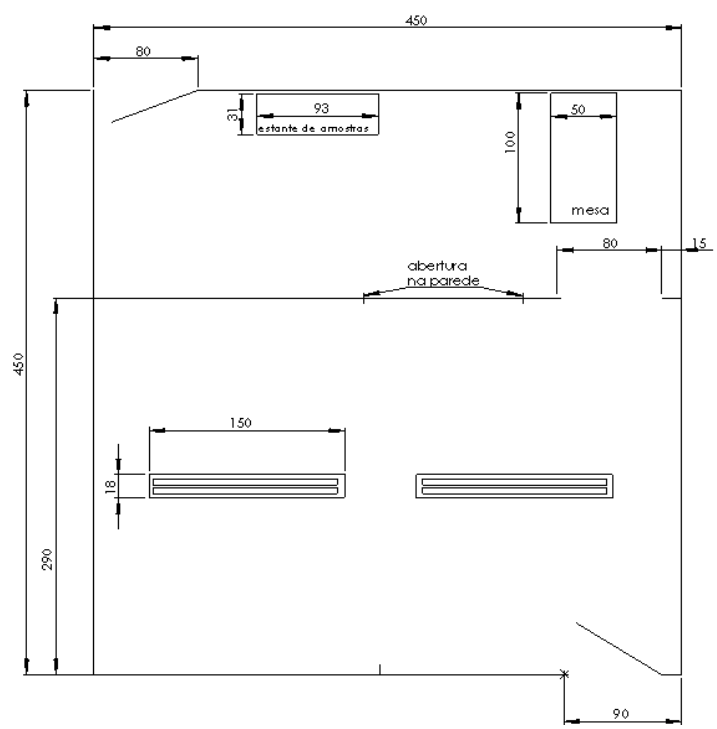

Figure 14: Change of the position of the tables

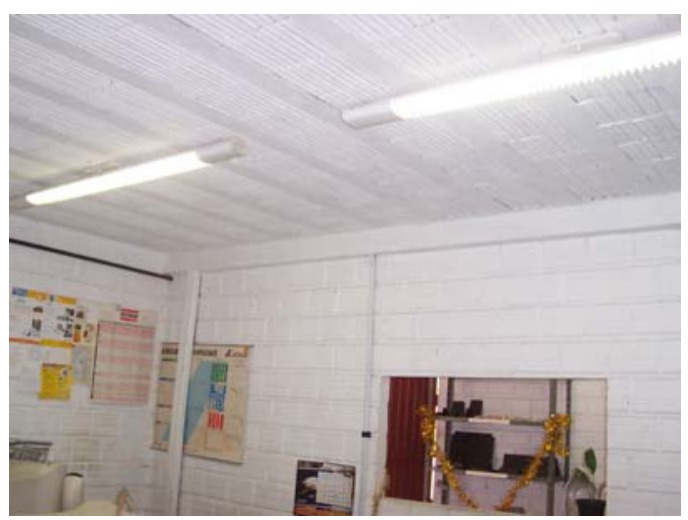

Figure 15: Lightning distribution of the room

The walls of the room will remain white because white reflects light thereby generating an almost-total lighting in the room, without a lot of bulbs.

The chairs were replaced by chairs in ergonomic design, thus avoiding the high discomfort to the collaborator.

This change in the company's office will have an estimated cost of $\mathrm{R} \$ 3,400.00$ for the purchase of three straight tables, a corner table, four ergonometric chairs and the specialized workmanship for changing the electrical outlets and modifying the wall corridor.

\section{Conclusion}

With the change of layout we have a better arrangement in the physical space available with a better distribution of workplaces and their equipment. The comfort of the new arrangement and workplaces was reported as positive by human resources, especially the position of the computer keyboard, the new more ergonomic chairs and adapted worktables and more free space on the workplace.

According to the board of the company, changes in the layout have been approved and will be made as soon as possible.

The new arrangement provided more physical comfort of the team due to changes in it, thus generating an increase in productivity and welfare in the work team. It also made possible a better attendance to the clients that need the sector, due to the disposition of the worktables in relation to the entrance.

\section{References}

[1] Chaffin, Don B.; Andersson, Gunnar B. J.; Martin, Bernard J. Biomecânica Ocupacional. Trad. Fernanda Saltiel Barbosa da Silva. Belo Horizonte: Ergo. 2001. 579 p.

[2] Duarte, Luiz Carlos da Silva. Introdução ao Estudo do Trabalho. Coleção Cadernos Unijuí - Série Engenharia de Produção, $n^{\circ}$ 01. Ijuí Ed. Unijuí, 2005. 64 p.

[3] Soares, Marcelo. Ergonomia: Princípios e Métodos. Universidade Federal de Pernambuco. Curso de Extensão. 2009

[4] Grandjean, Etienne. Manual de Ergonomia: adaptando o trabalho ao homem. $4^{\text {a }}$ ed. Trad. João Pedro Stein. Porto Alegre, RS: Artes Médicas, 1998. 338 p.

[5] Guimarães, Lia Buarque de Macedo. Ergonomia de processo 1. $2^{\mathrm{a}}$ ed. Porto Alegre, RS: Universidade Federal do Rio Grande do Sul, Escola de Engenharia - Programa de PósGraduação em Engenharia de Produção. 1999.

[6] Iida, Itiro. Ergonomia: Projeto e Produção. $4^{\text {a }}$ reimp. São Paulo, SP: Edgard Blücher, 1997. 465 p. 